\title{
A Novel Method for Tooth Bending Stress Calculation of Gears With Asymmetric Teeth
}

Oguz DOGAN

Kahramanmaras Sutcu Imam University

Celalettin YUCE

Bursa Technical University

Fatih KARPAT ( $\sim$ karpat@uludag.edu.tr)

Bursa Uludag University https://orcid.org/0000-0001-8474-7328

Original Article

Keywords: Gear bending stress, asymmetric gears, DIN 3990, finite element method

Posted Date: August 6th, 2021

DOI: https://doi.org/10.21203/rs.3.rs-758867/v1

License: (1) This work is licensed under a Creative Commons Attribution 4.0 International License.

Read Full License 


\title{
A Novel Method for Tooth Bending Stress Calculation of Gears with Asymmetric Teeth
}

\author{
Oguz DOGAN ${ }^{1}$, Celalettin YUCE $^{2}$, Fatih KARPAT*3 ${ }^{3}$
}
${ }^{1}$ Kahramanmaras Sutcu Imam University, Department of Mechanical Engineering, 46040, Kahramanmaras - Turkey - oguzdogan@ksu.edu.tr
${ }^{2}$ Bursa Technical University, Mechatronics Engineering Department, 16310, Bursa - Turkey - celalettin.yuce@btu.edu.tr
${ }^{3}$ Bursa Uludag University, Department of Mechanical Engineering, 16059, Bursa - Turkey - karpat@uludag.edu.tr

$\therefore$ Corresponding author: Prof. Dr. Fatih KARPAT

Tel.: +902242941930

E-mail address: karpat@uludag.edu.tr

ORCID: https://orcid.org/0000-0001-8474-7328 


\begin{abstract}
Today, gear designs with asymmetric tooth profiles offer essential solutions in reducing tooth root stresses of gears. Although numerical, analytical, and experimental studies are carried out to calculate the bending stresses in gears with asymmetric tooth profiles a standard or a simplified equation or empirical statement has not been encountered in the literature. In this study, a novel bending stress calculation procedure for gears with asymmetric tooth profiles is developed using both the DIN3990 standard and the finite element method. The bending stresses of gears with symmetrical profile were determined by the developed finite element model and was verified by comparing the results with the DIN 3990 standard. Using the verified finite element model, by changing the drive side pressure angle between $20^{\circ}$ and $30^{\circ}$ and the number of teeth between 18 and 100, 66 different cases were examined and the bending stresses in gears with asymmetric profile were determined. As a result of the analysis, a new asymmetric factor was derived. By adding the obtained asymmetric factor to the DIN 3390 formula, a new equation has been derived to be used in tooth bending stresses of gears with asymmetric profile. Thanks to this equation, designers will be able to calculate tooth bending stresses with high precision in gears with asymmetric tooth profile without the need for finite element analysis.
\end{abstract}

\title{
Highlights
}

- A new method has been proposed for calculating the bending stresses of gears with asymmetrical tooth profile.

- The finite element model are validated with the DIN 3990 for symmetric gears.

- The effects of drive side pressure angle and number of teeth on bending stress are investigated in 66 different cases.

- A novel asymmetry factor is proposed for the calculation of bending stress for gears with asymmetric teeth.

Key Words: Gear bending stress, asymmetric gears, DIN 3990, finite element method 


\section{INTRODUCTION}

Today, increasing sustainability concerns have made gears that provide high-efficiency power transmission a priority target in many industries, especially in the automobile, aviation, and machinery sectors. Research and development on the gear systems focused on meeting the demands of higher load-carrying capacity, weight reduction, and more torque transmission with low-cost gears [1]. New gear designs are needed to meet these performance expectations.

Most gears used today have teeth with a symmetric profile. In these gears, since the pressure angle of both surfaces is equal, the contact and bending stresses on both surfaces of the tooth are equal. During transmitting motion or power, gears generally operate in one direction. For this reason, while one side of the tooth, which is called the drive side, is exposed to high loads during its lifetime, there is no loading on the other side of the tooth, which is called the coast side. This situation has led to the design of gears with asymmetric profiles [2]. The most important advantage of the asymmetrical profile teeth is that they allow higher torque transmission by reducing the contact stress on the drive side [3]. Another significant advantage is that the tooth stiffness can be controlled by designing the drive side pressure angle (DSPA) different from the coast side. In this way, the vibration and noise of the gear pair working together are reduced [4]. Due to these advantages, the use of involute spur gears with an asymmetric profile is rapidly increasing, especially in areas with high-performance expectations.

During the torque transfer, high stresses, especially at the local contact line and root regions of the involute gears, cause fracture damages. These stresses in the root area, called bending stresses, are a critical performance indicator for gear designers as they cause damage and loss of performance [5]. Bending stresses can be calculated analytically using standard parameters for gears with symmetrical profile with the help of norms such as ISO 6336-1:2019 [6], ANSI/AGMA 2001 - D04 [7] and DIN 3990 [8]. However, the previously mentioned standard calculation methods are not valid, as maximum stress does not occur at the $30^{\circ}$ tangent of the root fillet in teeth with asymmetrical profiles. These methods differ somewhat in the techniques used to establish the gear geometry required for this calculation and their stress concentration factors[9].

Today, experimental methods have been used to determine the bending stresses [10-12], impact stress [13] and fatigue properties [14] of gears with asymmetrical profiles. However, these methods find limited application areas due to their long duration and high costs. The most important problem experienced in measuring root stress with experimental methods is the error of the positional accuracy of the gauge, especially in small modulus gears[9]. Therefore, many researchers have carried out analytically studies on the stress analysis of gears with asymmetrical profiles in recent years. Although some results can be obtained with analytical methods, it is not possible to obtain exact results due to the complex geometries of the gears and the coefficients used in the calculations. For this reason, the finite element method (FEM) has started to be used by many researchers in the calculation of tooth bending stress. Cavdar et al. [15] examined the bending stresses and contact ratio depending on the DSPA by adapting the DIN 3990 and ISO 6336-1:2019 norms to the asymmetric tooth 
profile. They stated that with the increase of the DSPA, the bending load capacity increased while the bending stress decreased. Spitas and Spitas [16] optimized the tooth geometry to achieve minimum tooth root stress in non-standard involute gears. The optimized tooth design achieved an $8.5 \%$ reduction in root stress and confirmed this result experimentally.

Karpat et al. [17] and Di Francesco and Marini [18] have developed several computer programs to optimize the tooth design to achieve maximum performance from asymmetric gear. Costopoulos and Spitas [19] have achieved a 28\% increase in load-carrying capacity with their asymmetric gear designs than teeth with a symmetric profile. Karpat et al. [20] performed finite element analysis (FEA) using a 2D tooth model to calculate tooth stiffness for dynamic analysis depending on the DSPA and the number of teeth. Pedersen [21] showed that the bending stress reduced with the optimized asymmetric gear design obtained by changing the tool geometry. Senthil Kumar et al. [22] investigated the influence of pressure angle, asymmetric factors, and profile shift on the maximum fillet stress to propose the optimum parameter levels that improve the fillet bending capacity. They also compared the FEA model results they used in their studies with ISO 6336-1:2019 and ANSI/AGMA 2001D04 standards for symmetric gears. Sekar and Muthuveerappan [23] determined the tooth form factor for asymmetric gears with different DSPA and Coast Side Pressure Angles (CSPA) with the ISO 6336-1:2019 standard. They adapted using FEM. Marimuthu and Muthuveerappan [24] also adopted a FEM to compare directly designed symmetrical and asymmetrical High Contact Ratio (HCR) spur gears and traditional symmetrical HCR spur gears for their load-carrying capacity. Lisle et al. [9] compared the root bending stress of spur gear calculated by ISO, AGMA and FEA methods with the experimental results and stated that more accuracy results can be obtained with FEA. Thomas et al. [25] applied a search method to calculate the bending stress of asymmetric spur gear, and they compared the results with ISO 6336-1:2019 and FEA methods. They propose a new method and coordinate system for the calculation of bending stress of spur gears with asymmetric teeth analytically.

In the literature review, it was seen that, although there are standards based on analytical methods to determine the bending stresses of gears with symmetric profile, a standard is not available for gears with asymmetric teeth profile. Experimental and numerical studies have been carried out to determine the bending stresses of gears with asymmetric teeth. However, the lack of a simplified equation or empirical statement that will allow gear designers to get to the conclusion faster is a significant drawback. As well as, although FEA has the ability to be incredibly accurate, it requires no gear expertise and can produce wrong and misleading results often as a consequence of over simplified gear models, incorrect boundary conditions and poor mesh quality [9].

This study proposes a novel bending stress calculation method based on DIN 3990 / Method $\mathrm{C}$ and FEA analysis for gear with asymmetric teeth. The effects of DSPA and tooth number on the bending stress is evaluated numerically. A novel bending stress calculation factor called the asymmetry factor is proposed using the maximum bending root stress results from the FEA. The maximum root bending stress can be easily calculated using the proposed asymmetry factor and DIN 3990 / Method C standard for gears with asymmetric teeth. The asymmetry factor has simplified the calculation of the gear root bending stress. The stress 
values can be analytically calculated by using this factor, without any numerical or experimental study.

\section{MATERIAL AND METHOD}

\subsection{Creation of the Gear Geometry}

In this study, gear geometries were created by mathematical modeling based on Litvin's vector method. In this method, firstly, the equations and limits of the rack cutter tool, which manufactured the gears, is determined. Then the spur gear geometry is created using the coordinate transformation, differential geometry, and gear theory. The geometry of the rack type cutting tool is seen in Fig. 1. In this geometry, the ac - bd zones shape the bottom region of the gear; the ce - df zones shape the trochoid zone of the gear, and the eg - fh zones shape the involute zone of the gear wheel. $\mathrm{O}(\mathrm{X}, \mathrm{Y})$ is positioned in the middle of the space width. More detail about the creation of the gear geometries is given in [26].

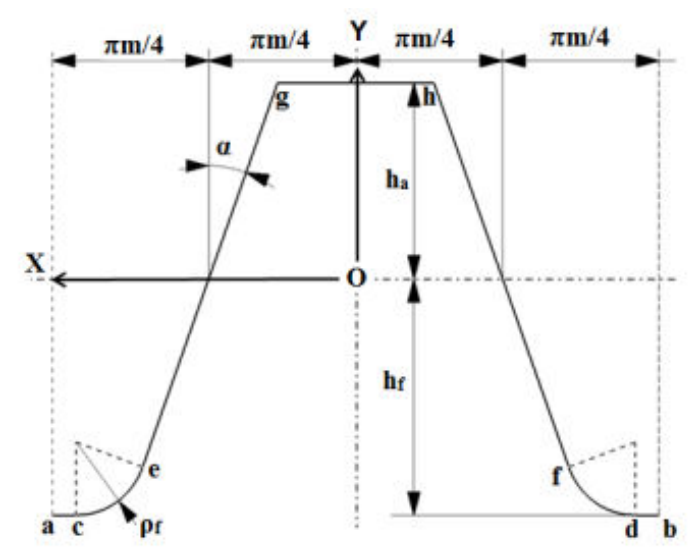

Fig 1. The geometry of the rack type cutter tool

\subsection{Calculation of Tooth Bending Stress via DIN3990}

In the literature, different standards have been developed so far to calculate bending stress in evolvent spur gears with symmetric teeth. Among them, ISO 6336-1:2019 [6] and DIN 3990 [8] standards are the most widely used. Although they are similar to each other, there are some minor differences. With these standards, the following assumptions are used in the calculation of tooth bending stress;

- The critical section of the tooth is the thickness of the point tangent to the tooth root at an angle of $30^{\circ}$, starting from the axis of tooth symmetry (Fig. 2).

- The compressive stress caused by the radial component of the normal force on the gear is negligible.

- In DIN 3990 / Method C and ISO 6336-1:2019, the tooth load is assumed to effect on the tip of the teeth.

In this study, the calculations were done according to the DIN 3990 / Method C. So, the force was applied to the addendum circle of the teeth. 


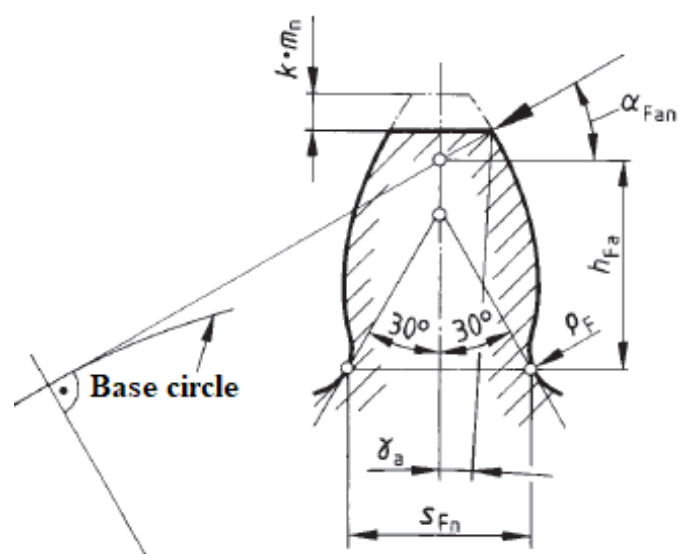

Fig 2. Tooth model for bending stress DIN 3990 / Method C [8]

According to the DIN 3990 / Method C, the maximum tooth root stress can be calculated by using Eq. 1.

$\sigma_{\mathrm{F} 0-\mathrm{C}}=\frac{\mathrm{F}_{\mathrm{t}}}{\mathrm{b} \mathrm{m}_{\mathrm{n}}} \mathrm{Y}_{\mathrm{Fa}} \mathrm{Y}_{\mathrm{Sa}} \mathrm{Y}_{\varepsilon} \mathrm{Y}_{\beta}$

$F_{t}=F \cos \alpha$

Where; $\mathrm{F}_{\mathrm{t}}$ tangential gear force, $\mathrm{b}$ tooth width, $\mathrm{m}_{\mathrm{n}}$ is defined as a normal module.

$\mathrm{Y}_{\mathrm{Fa}}$ tooth form factor can be defined as,

$Y_{F a}=\frac{6\left(h_{F a} / m_{n}\right)}{\left(S_{F n} / m_{n}\right)^{2}} \frac{\cos \alpha_{F a n}}{\cos a_{n}}$

$Y_{S a}$ stress concentration factor can be defined as,

$Y_{S a}=\left(1.2+0.13 \frac{S_{F n}}{h_{F a}}\right)\left(\frac{S_{F n}}{2 \rho_{F}}\right)^{1 /\left[1.21+2.3\left(h_{F a} / S_{F n}\right)\right]}$

$Y_{\varepsilon}$ load sharing factor (Contact factor) can be calculated via Eq. 5.

$Y_{\varepsilon}=0.25+0.75 / \varepsilon_{\alpha}$

Where, $\varepsilon \alpha$ is the contact ratio of the spur gear pair and can be calculated as the Eq. 6 .

$\varepsilon_{\alpha}=\frac{\sqrt{r_{a 1}^{2}-r_{b 1}^{2}}+\sqrt{r_{a 2}^{2}-r_{b 2}^{2}}-a_{d} \sin \alpha_{d}}{p \cos \alpha_{d}}$

Where, $r_{\mathrm{a} 1}, \mathrm{r}_{\mathrm{b} 1}, \mathrm{r}_{\mathrm{a} 2}, \mathrm{r}_{\mathrm{b} 2}$ addendum and base circles of the pinion and gear, $\mathrm{a}_{\mathrm{d}}$ is the distance between axes, $\alpha_{d}$ is the drive side pressure angle, $p$ is pitch. 
In this study, bending stress was calculated on a single tooth using the finite element method. Therefore, some assumptions have been made. The load sharing factor $\left(Y_{\varepsilon}\right)$ was not taken into account in the calculations. The single tooth load was applied to the tip of the tooth and since the helix angle is zero on spur gears the helix factor $Y_{\beta}$ is determined as 1 . Form factor $\left(\mathrm{Y}_{\mathrm{Fa}}\right)$ and stress concentration factor $\left(\mathrm{Y}_{\mathrm{Sa}}\right)$ values are changed depending on the several parameters such as, tool geometry, addendum, dedendum, tooth number, profile shifting factor, rack cutter tip radius, etc. In the well-known standards such as DIN 3990 and ISO 6336-1:2019, many graphics or tables are required to get these factors. According to the DIN 3990 standard, for the

rack cutter tip radius $\left(\rho_{\mathrm{F}}\right)$ of $0.3 \mathrm{~m}$, the variation of the $\mathrm{Y}_{\mathrm{Fa}}$ and $\mathrm{Y}_{\mathrm{Sa}}$ is given in Fig. 3 . Moreover, these coefficients can be calculated by using Eq. 3 and Eq. 4. The equations are more suitable for computer programming than the tables. However, to calculate $\mathrm{Y}_{\mathrm{Fa}}$ and $\mathrm{Y}_{\mathrm{Sa}}$ by using the equations, the moment arm length $\left(\mathrm{h}_{\mathrm{Fa}}\right)$, rack cutter tip radius $\left(\rho_{\mathrm{F}}\right)$ critical tooth thickness $\left(\mathrm{S}_{\mathrm{Fn}}\right)$ should be determined for each tooth number and pressure angle.
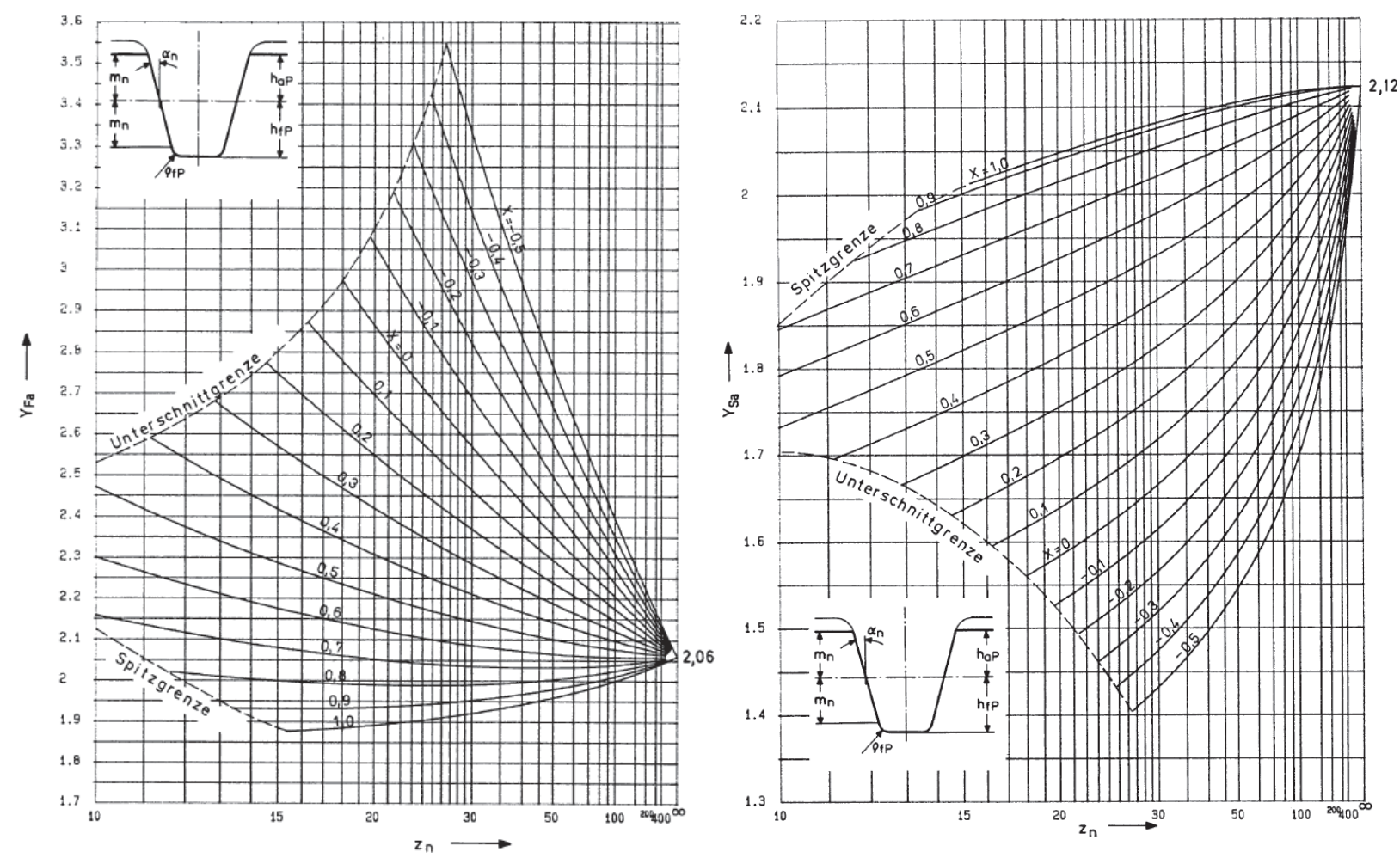

Fig 3. The variation of $\mathrm{Y}_{\mathrm{Fa}}$ (Form factor) and $\mathrm{Y}_{\mathrm{Sa}}$ (Stress concentration factor) according to DIN3990 for $\rho_{\mathrm{F}}=0.3 \mathrm{~m}[8]$

\subsection{Finite Element Analysis Procedure}

Finite element stress analyses were conducted for the determination of the stress distribution of the gears. Moreover, the effects of DSPA and tooth number on the maximum bending stress were investigated numerically. The general finite element stress analysis procedure is divided into five steps as designing the gear geometry, creating the mesh structure, defining the boundary conditions of the analysis, running the analysis, and evaluating the results.

The gear geometries were created according to Litvin's vector method described in Section 2.1. And the CAD model was imported to the ANSYS Workbench static structural module for 
the stress analysis. The mesh structure of the finite element model consisted of approximately 45000 hexahedral (Solid186 and Solid187) elements and 180000 nodes. The general view of the mesh structure of the finite element model is seen in Fig. 4.a. A mesh convergence study with different mesh sizes for $20^{\circ}-20^{\circ}$ pressure angle and 20 tooth number was performed. As a result of the convergence, it was observed that there was no significant change in the results after approximately 45000 elements (Fig. 4.b).

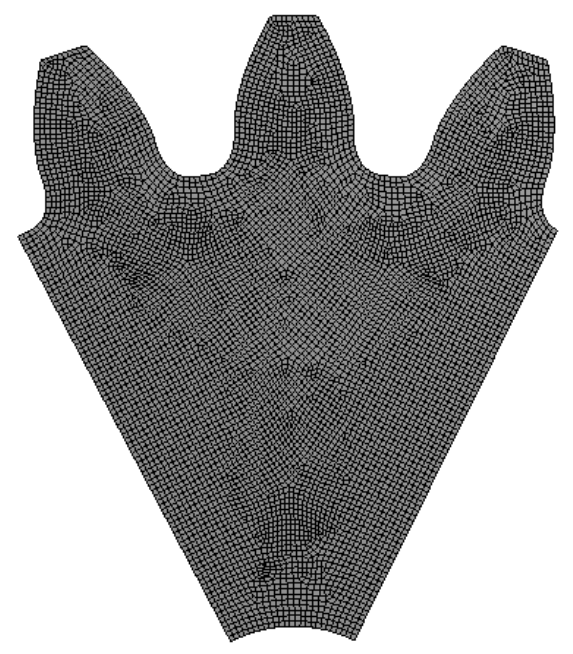

a)

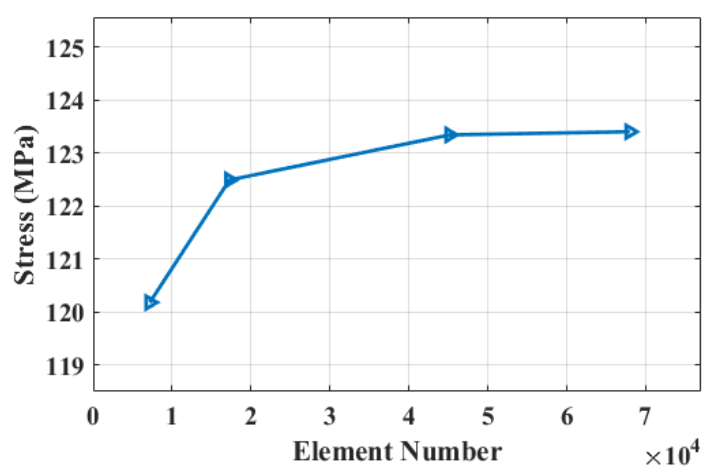

b)

Fig 4. a) Mesh structure of finite element model b) Mesh convergence results

After creating the mesh structure of the finite element model, the boundary conditions were defined according to the DIN 3990 / Method C (Fig. 5). In this method, a single tooth load applies on the tip of the tooth at the tangent direction of the base circle, as seen in Fig. 2. The pressure angle on the addendum circle is calculated by Eq. 7, and the tangential component of the force is calculated by Eq. 8. In the FEA, $100 \mathrm{~N}$ static force was applied on the tip of the tooth, and according to the DIN 3990 /Method C standard, the gear geometry was entirely fixed on the side and bottom surfaces.

$$
\begin{aligned}
& \mathrm{r}_{0} \cos \alpha=\mathrm{r}_{\mathrm{a}} \cos \alpha_{\mathrm{a}} \\
& F_{t}=F \cos \alpha_{\mathrm{a}}
\end{aligned}
$$

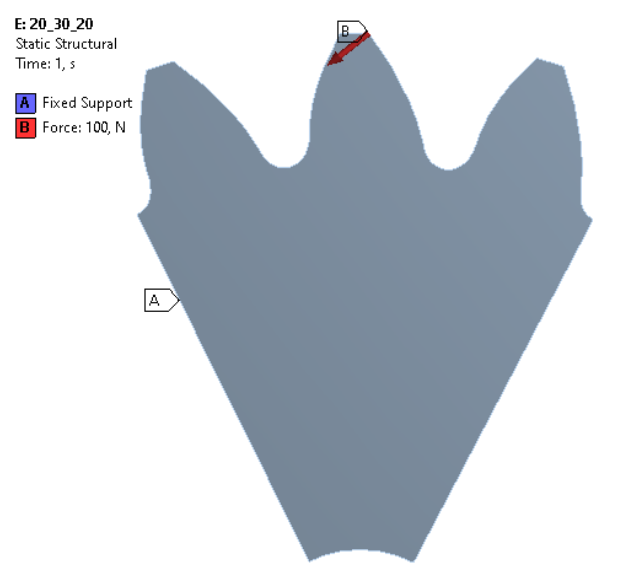


Fig 5. The boundary conditions of the FEA

The main properties of the gear used in this study were given in Table 1 . To investigate the effect of DSPA, six different values, $20^{\circ}, 22^{\circ}, 24^{\circ}, 26^{\circ}, 28^{\circ}$ and $30^{\circ}$ were determined. For the number of teeth, eleven different values between 18 and 100 were determined. This value was determined as the minimum, since undercut was observed on the spur gears in values below 18 teeth. Moreover, the number of teeth was not increased to avoid the number of analyses since there were not many real samples above 100 teeth.

Table 1. Gear properties of the study

\begin{tabular}{l|l} 
Gear Property & Value \\
\hline Material & S235 (Steel) \\
Modulus of Elasticity $(\mathrm{E})(\mathrm{MPa})$ & 205000 \\
Poisson Ratio $(\mathrm{v})$ & 0.3 \\
Density $(\rho)\left(\mathrm{kg} / \mathrm{m}^{3}\right)$ & 7850 \\
Module $(\mathrm{m})(\mathrm{mm})$ & 3.18 \\
Coast side pressure angle $\left(\alpha_{\mathrm{c}}\right)(\mathrm{deg})$ & 20 \\
Drive side pressure angle $\left(\alpha_{\mathrm{d}}\right)(\mathrm{deg})$ & $20-22-24-26-28-30$ \\
Tooth number $(\mathrm{z})$ & $18-20-23-28-30-35-40-50-70-80-100$ \\
Addendum $(\mathrm{ha})$ & $1 \mathrm{~m}$ \\
Dedendum $(\mathrm{hf})$ & $1.25 \mathrm{~m}$ \\
Face width $(\mathrm{b})(\mathrm{mm})$ & 1 \\
Rack cutter tip radius $\left(\rho_{\mathrm{F}}\right)$ & $0.3 \mathrm{~m}$
\end{tabular}

After the finite element model was created, static structural analysis was performed. The basic finite element equation to be solved for static loads can be expressed as:

$\{\mathrm{F}\}=[\mathrm{K}]\{\mathrm{u}\}$

Where $\mathrm{F}$ is the applied load vector, $\mathrm{K}$ is the stiffness matrix, and $\mathrm{u}$ is the displacement vector. Hooke's law was used to calculate the stress distribution of the finite element model. The Hooke's law is written in the following Eq. 10.

$[\sigma]=[E][\varepsilon]$

\section{RESULTS AND DISCUSSION}

Within the scope of this study, a total of 66 finite element analyzes were carried out for eleven different tooth numbers and six different DSPAs, and maximum bending stresses were examined. Then, the obtained FEA results were compared with the bending stress results calculated in accordance with the DIN 3990 method. As an example of the analysis the FEA results for symmetric profile $\left(\alpha_{c}=20^{\circ}, \alpha_{d}=20^{\circ}\right)$ and different tooth numbers $(18,23,30,40,70$, and 100) were seen in Fig 6. As can be seen in Table 2, where FEA and analytical method are compared, the results obtained are quite consistent with each other. The maximum relative error between DIN 3990 and FEA was under 2\%. When the bending stresses were investigated for the symmetric case, the stress decreased with the increase in the tooth 
number. The maximum bending stress values slightly increased when the tooth number increased above 40 and stayed stable according to FEA and DIN 3990.

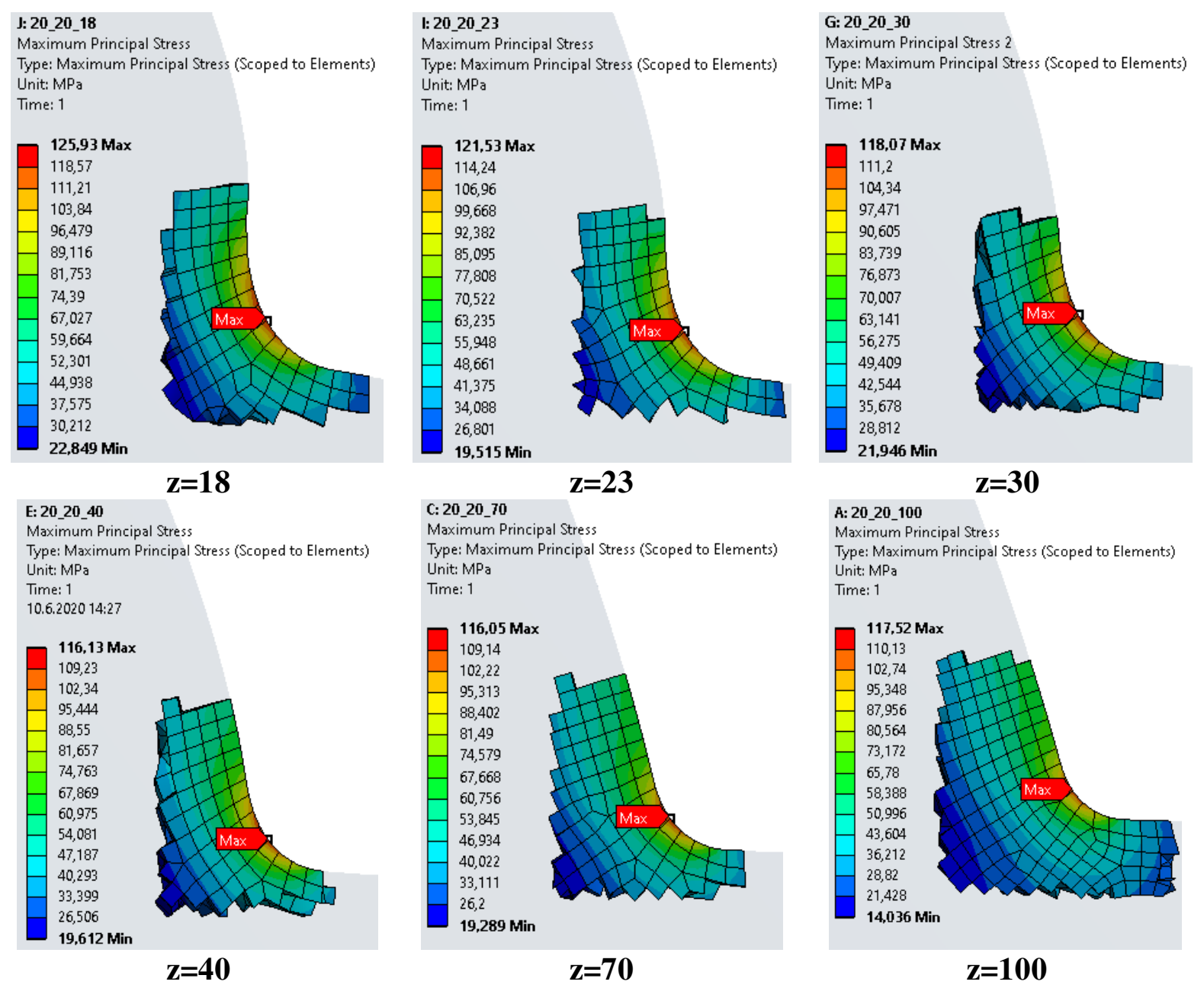

Fig 6. Finite element analysis results for $\alpha_{c}=20^{\circ}, \alpha_{c}=20^{\circ}$, and different tooth numbers

Table 2. Comparison of DIN3990 and FEA results of maximum fillet stress for symmetric case $\left(20^{\circ}-20^{\circ}\right)$

\begin{tabular}{c|ccc}
$\begin{array}{c}\text { Z (Teeth } \\
\text { Number })\end{array}$ & $\begin{array}{c}\text { DIN3990 } \\
\left(\boldsymbol{\sigma}_{\mathbf{F 0}-\mathbf{C}}\right)\end{array}$ & $\begin{array}{c}\text { FEA } \\
\left(\boldsymbol{\sigma}_{\mathbf{F} 0-\mathbf{C}}\right)\end{array}$ & $\begin{array}{c}\boldsymbol{\%} \\
\text { Error }\end{array}$ \\
\hline 18 & 124.03 & 125.93 & -1.53 \\
20 & 121.81 & 123.34 & -1.25 \\
23 & 120.89 & 121.53 & -0.52 \\
28 & 119.59 & 118.84 & 0.62 \\
30 & 118.89 & 118.07 & 0.69 \\
35 & 116.80 & 116.84 & -0.02 \\
40 & 117.14 & 116.13 & 0.86 \\
50 & 118.35 & 116.87 & 1.25 \\
70 & 118.11 & 116.06 & 1.79 \\
80 & 118.81 & 117.17 & 1.38
\end{tabular}


To obtain $\mathrm{Y}_{\mathrm{Fa}}{ }^{*} \mathrm{Y}_{\mathrm{Sa}}$ values for tooth with symmetrical profile, maximum bending stresses obtained both from FEA and DIN 3990 norm are normalized using Eq. 11.

$\mathrm{Y}_{\mathrm{Fa}} \mathrm{Y}_{\mathrm{Sa}}=\sigma_{\mathrm{F} 0-\mathrm{C}} \frac{\mathrm{b} \mathrm{m}}{\mathrm{F}_{\mathrm{t}}}$

The variation of $\mathrm{Y}_{\mathrm{Fa}}{ }^{*} \mathrm{Y}_{\mathrm{Sa}}$ values depending on the number of teeth was given in Fig. 7. The results indicated that both FEA and DIN3990 results were compatible with each other. The value of $\mathrm{Y}_{\mathrm{Fa}}{ }^{*} \mathrm{Y}_{\mathrm{Sa}}$ was nearly 4.8 for 18 tooth number. The $\mathrm{Y}_{\mathrm{Fa}} * \mathrm{Y}_{\mathrm{Sa}}$ value decreased until the tooth number 40. A small fluctuation was observed in the values obtained with FEA results in the range of 80 to 100 teeth.

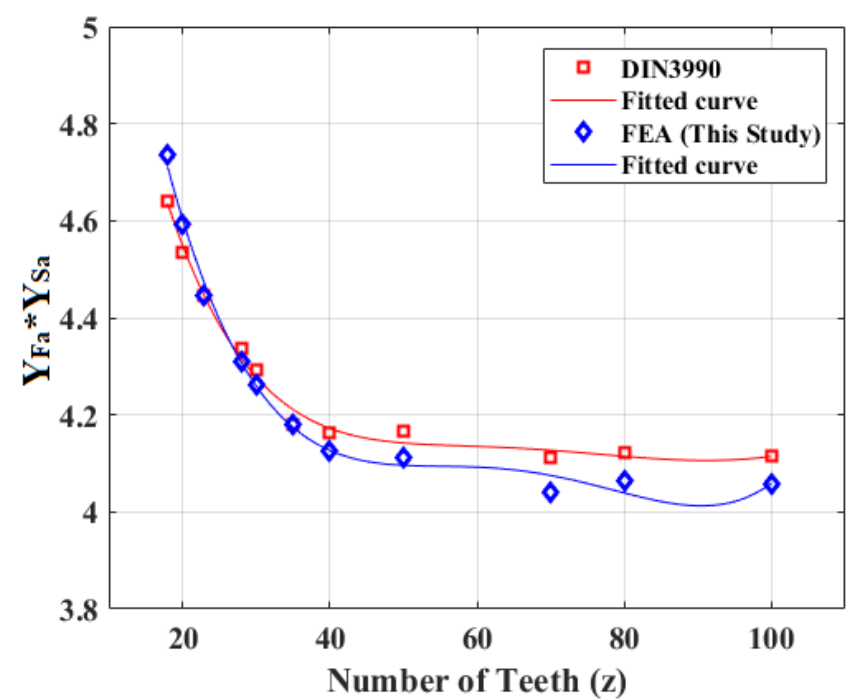

Fig 7. Comparison of $\mathrm{Y}_{\mathrm{Fa}} * \mathrm{Y}_{\mathrm{Sa}}$ variation of DIN3990 with finite element analysis

After the maximum bending stresses obtained with the finite element model created for the symmetrical tooth profile were verified with the analytical values calculated according to the DIN 3990 standards, this finite element model was started to be used in gears with asymmetrical profile. The FEA results for eleven different tooth numbers and six different DSPA values were given in Table 3. The results showed that DSPA and tooth number have a significant effect on maximum bending stress. When the DSPA increased, the bending stress was decreased considerably. Approximately the bending stresses were reduced between $20-$ $25 \%$ depending on the tooth number. The DSPA effect was increased with the increase in the tooth number. The bending stress decreased with the increase in the tooth number nearly until 40 . 
Table 3. Maximum fillet stress results obtained with FEA (MPa)

\begin{tabular}{|c|c|c|c|c|c|c|c|}
\hline & \multicolumn{6}{|c|}{ Drive Side Pressure Angle $-\alpha_{d}\left({ }^{\circ}\right)$} \\
\hline & & 20 & 22 & 24 & 26 & 28 & 30 \\
\hline \multirow{11}{*}{ 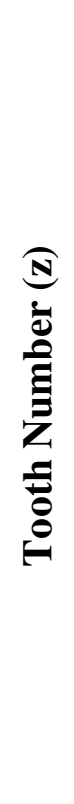 } & 18 & 125.93 & 120.69 & 115.81 & 110.84 & 106.01 & 100.88 \\
\hline & 20 & 123.34 & 118.38 & 113.62 & 108.59 & 103.29 & 98.044 \\
\hline & 23 & 121.53 & 116.15 & 110.91 & 105.76 & 101.03 & 95.992 \\
\hline & 28 & 118.84 & 113.38 & 108.28 & 103.13 & 98.593 & 93.529 \\
\hline & 30 & 118.07 & 112.57 & 107.27 & 102.57 & 97.291 & 92.273 \\
\hline & 35 & 116.84 & 111.96 & 106.90 & 101.88 & 95.964 & 91.396 \\
\hline & 40 & 116.13 & 111.62 & 106.06 & 101.43 & 94.985 & 90.825 \\
\hline & 50 & 116.87 & 111.29 & 105.73 & 99.377 & 94.802 & 89.743 \\
\hline & 70 & 116.05 & 111.21 & 104.31 & 98.560 & 93.133 & 88.562 \\
\hline & 80 & 117.17 & 110.96 & 104.40 & 98.055 & 93.093 & 88.061 \\
\hline & 100 & 117.52 & 110.59 & 104.06 & 98.471 & 93.276 & 88.438 \\
\hline
\end{tabular}

The main goal of this study was to develop a simplified empirical equation in accordance with the DIN 3990 norm using the FEA results to calculate the bending stress of teeth with an asymmetric profile. Accordingly, the normalization process was carried out to obtain a factor called asymmetric factor $\left(\mathrm{K}_{\alpha \mathrm{d}}\right)$. The maximum bending stress values obtained with FEA shown in Table 3 were normalized using Eq. 12.

$\mathrm{K}_{\alpha \mathrm{d}}=\frac{\left.\sigma_{\mathrm{F} 0-\mathrm{C}\left(20^{\circ}-\alpha_{\mathrm{d}}\right)}\right)}{\sigma_{\mathrm{F} 0-\mathrm{C}\left(20^{\circ}-20^{\circ}\right)}}$

where $\mathrm{K}_{\alpha \mathrm{d}}$ is a new coefficient for calculating asymmetric gears bending stress, $\sigma_{\mathrm{F} 0-\mathrm{C}\left(20^{\circ}-20^{\circ}\right)}$ is the results for symmetric cases and $\sigma_{\mathrm{F} 0-\mathrm{C}\left(20^{\circ}-\alpha_{d}\right)^{\circ}}$ is the results for asymmetric cases in Table 3. The asymmetric factors obtained using Eq. 12 as a result of normalization depending on different tooth number and DSPA are given in Table 4. The results show that both the number of teeth and the DSPA are very important on the asymmetric factor. With increasing DSPA, the asymmetric factor decreased. Furthermore, as a result of the increase in the number of teeth in constant DSPA, there was a decrease in the asymmetric factor again. These results showed that in teeth with asymmetric profile, root stresses decrease due to the increase in the pressure angle. The reason can be explained as the thickness in the critical section of the tooth increases, and the stress values decrease with the pressure angle increase. 
Table 4. Asymmetric factors $\left(\mathrm{K}_{\mathrm{\alpha d}}\right)$ depending on the DSPA and tooth number

\begin{tabular}{|c|c|c|c|c|c|c|c|}
\hline & \multicolumn{6}{|c|}{ Drive Side Pressure Angle $-\alpha_{d}\left({ }^{\circ}\right)$} \\
\hline & & 20 & 22 & 24 & 26 & 28 & 30 \\
\hline \multirow{11}{*}{ 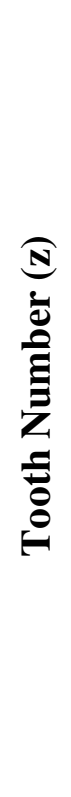 } & 18 & 1 & 0.958 & 0.919 & 0.880 & 0.841 & 0.801 \\
\hline & 20 & 1 & 0.959 & 0.921 & 0.880 & 0.837 & 0.794 \\
\hline & 23 & 1 & 0.955 & 0.912 & 0.870 & 0.831 & 0.789 \\
\hline & 28 & 1 & 0.954 & 0.911 & 0.867 & 0.829 & 0.787 \\
\hline & 30 & 1 & 0.953 & 0.908 & 0.868 & 0.824 & 0.781 \\
\hline & 35 & 1 & 0.958 & 0.914 & 0.871 & 0.821 & 0.782 \\
\hline & 40 & 1 & 0.961 & 0.913 & 0.873 & 0.817 & 0.782 \\
\hline & 50 & 1 & 0.952 & 0.904 & 0.850 & 0.811 & 0.767 \\
\hline & 70 & 1 & 0.958 & 0.898 & 0.849 & 0.802 & 0.763 \\
\hline & 80 & 1 & 0.947 & 0.891 & 0.836 & 0.794 & 0.751 \\
\hline & 100 & 1 & 0.941 & 0.885 & 0.837 & 0.793 & 0.752 \\
\hline
\end{tabular}

In addition, the variation of the asymmetric factor $\left(\mathrm{K}_{\alpha \mathrm{d}}\right)$ depending on the DSPA and the number of teeth is graphically shown in Fig. 8. As can be seen from the graph, the increase in DSPA decreased the asymmetric factor, that is, the maximum bending stress in the tooth decreased. The asymmetric factor decreased with the increase in the DSPA value until the number of teeth was 40 . According to the obtained results, it is seen that DSPA was more effective than tooth number on the asymmetric factor.

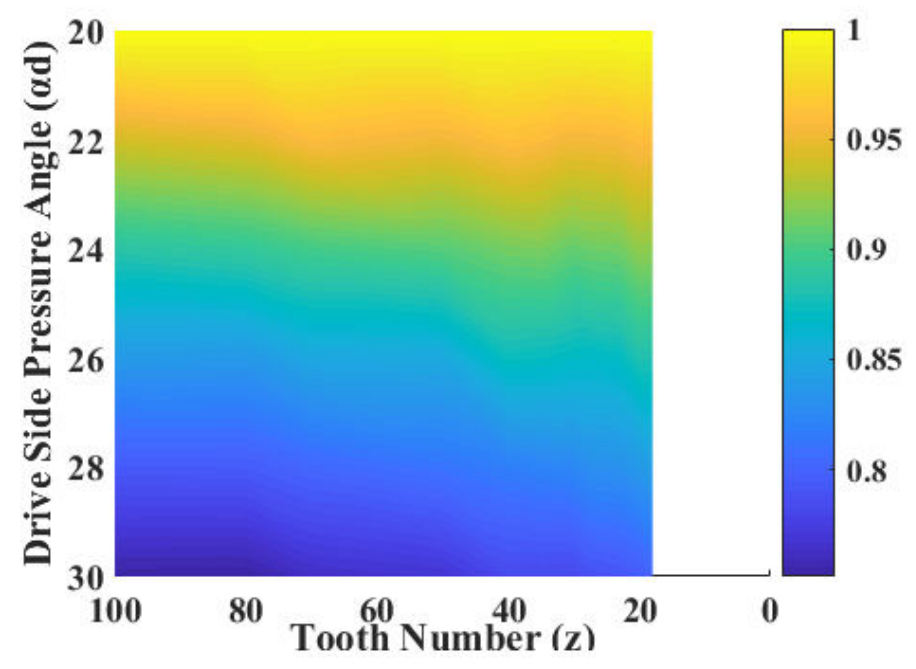

Fig 8. Variation of $\mathrm{K}_{\alpha \mathrm{d}}$ according to DSPA and tooth number 
Since one of the most important purposes in this study is to calculate the bending stress of gears with an asymmetric profile with a simplified equation, the variations in the asymmetric factor $\left(\mathrm{K}_{\alpha \mathrm{d}}\right)$ were investigated. As can be seen from Table 4 and Fig. 8, the variation of the asymmetric factor is linear. For this reason, Eq. 13 was used by considering the model to be created in the calculations to be linear.

Model $=\mathrm{A} \alpha+\mathrm{Bz}+\mathrm{C}$

Where $\alpha$ is the DSPA, $\mathrm{z}$ is the number of teeth. In this model, the coefficients of $\mathrm{A}, \mathrm{B}$ and C were calculated by surface fitting and linear regression methods. The determined coefficients of the model were; $\mathrm{A}=-0.02235, \mathrm{~B}=-0.0003825$ and $\mathrm{C}=1.4626$. The Eq. 14 , in which the asymmetric factor can be calculated depending on the number of teeth and the drive side pressure angle is given below, together with these coefficients.

$\mathrm{K}_{\alpha \mathrm{d}}=-0.02235 \alpha-0.0003825 \mathrm{z}+1.4626$

Equation 15 is obtained by including the asymmetric factor $\left(\mathrm{K}_{\alpha \mathrm{d}}\right)$ derived in this study into the equation that calculates the bending stress in gears with symmetrical profile according to the DIN 3990 / Method C. With the obtained modified equation, tooth bending stresses can be calculated analytically in asymmetric gears.

$\sigma_{\mathrm{F} 0-\mathrm{C}}=\frac{F_{t}}{\mathrm{~b} \cdot \mathrm{m}_{\mathrm{n}}} \mathrm{Y}_{\mathrm{Fa}} \cdot \mathrm{Y}_{\mathrm{Sa}} \cdot \mathrm{K}_{\alpha \mathrm{d}}$

In this study, tooth bending stresses of asymmetric gears were calculated with the obtained new empirical equation. Firstly, asymmetric factors $\left(\mathrm{K}_{\alpha \mathrm{d}}\right)$ were calculated using Eq. 14 for six different DSPAs and eleven different tooth numbers. Then, the obtained $\left(\mathrm{K}_{\alpha \mathrm{d}}\right)$ was used in the Eq. 15. The maximum bending stresses calculated with the modified empirical equation depending on the different pressure angles and the number of teeth are given in Table 5. As well as, to determine the accuracy of the empirical model developed in this study, the stress values obtained with the empirical equation were compared with the results of the finite element analysis. It was observed that there is a great agreement between the maximum bending stress values obtained using the modified empirical formula and the stresses obtained as a result of FEA. The maximum relative error was detected as $2.4 \%$ and the average relative error was around $1 \%$. These results show that the new empirical equation obtained with the method followed in the study gives very sensitive results. By using this new equation, bending stresses of asymmetric gears can be calculated analytically without the need for finite element analysis. 
Table 5. Maximum fillet stress results obtained with Eq. $15(\mathrm{MPa})$

\begin{tabular}{|c|c|c|c|c|c|c|c|}
\hline & \multicolumn{6}{|c|}{ Drive Side Pressure Angle $-\alpha_{d}\left({ }^{\circ}\right)$} \\
\hline & & 20 & 22 & 24 & 26 & 28 & 30 \\
\hline \multirow{11}{*}{ 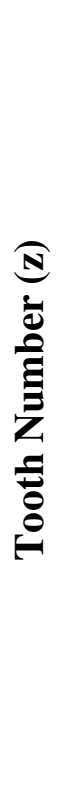 } & 18 & 124.03 & 118.82 & 113.98 & 109.15 & 104.31 & 99.35 \\
\hline & 20 & 121.81 & 116.82 & 112.19 & 107.19 & 101.95 & 96.72 \\
\hline & 23 & 120.89 & 115.45 & 110.25 & 105.17 & 100.46 & 95.38 \\
\hline & 28 & 119.59 & 114.09 & 108.95 & 103.68 & 99.14 & 94.12 \\
\hline & 30 & 118.89 & 113.30 & 107.95 & 103.20 & 97.97 & 92.85 \\
\hline & 35 & 116.80 & 111.89 & 106.76 & 101.73 & 95.89 & 91.34 \\
\hline & 40 & 117.14 & 112.57 & 106.95 & 102.26 & 95.70 & 91.60 \\
\hline & 50 & 118.35 & 112.67 & 106.99 & 100.60 & 95.98 & 90.77 \\
\hline & 70 & 118.11 & 113.15 & 106.06 & 100.28 & 94.72 & 90.12 \\
\hline & 80 & 118.81 & 112.51 & 105.86 & 99.33 & 94.34 & 89.23 \\
\hline & 100 & 119.18 & 112.15 & 105.47 & 99.75 & 94.51 & 89.62 \\
\hline
\end{tabular}

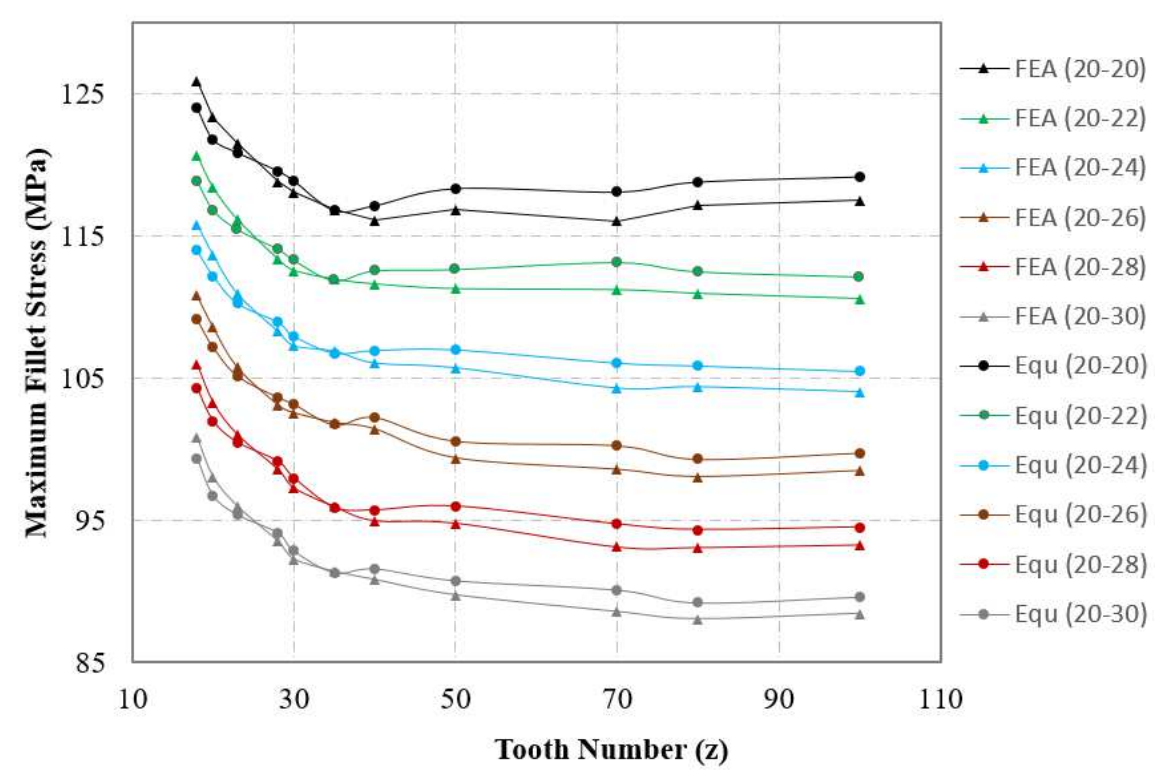

Fig 9. Comparison of maximum fillet stress results obtained with FEA and empirical equation

\section{CONCLUSIONS}


In this study, a simplified empirical equation has been developed to analytically calculate the maximum bending stress for gears with asymmetrical tooth profile, which is widely used in many critical sectors such as defense, energy and aerospace. While there are analytical methods determined by ISO 6336-1:2019, ANSI/AGMA 2001-D04 and DIN 3990 norms in the literature to calculate the maximum bending stresses of gears with symmetrical profile, there is no standard for asymmetric gears. In this study, maximum bending stresses of asymmetric teeth were calculated for six different drive side pressure angles and eleven different tooth numbers using the FE model validated on the symmetrical tooth. With the normalization of the stress results obtained from the FEA, the factor called asymmetric factor $\left(\mathrm{K}_{\mathrm{ad}}\right)$ was obtained. After the linear model created, asymmetric factors were calculated depending on the DSPA and the number of teeth. The empirical equation used to calculate the stresses in the symmetrical gears in the DIN 3990 / Method C was modified by adding asymmetric factor. In order to determine the accuracy of the empirical model developed in this study, the stress values obtained with the empirical equation were compared with the results of the FEA. It was observed that there is a great agreement between the maximum bending stress values obtained using the modified empirical formula and the stresses obtained as a result of FEA. The maximum relative error was detected as $2.4 \%$ and the average relative error was around $1 \%$. Thanks to the empirical equation obtained, it has been seen that the bending stresses of asymmetric gears can be calculated with high accuracy without the need for finite element analysis.

\section{NOMENCLATURE}

$\begin{array}{ll}\alpha & : \text { Pressure angle } \\ \alpha_{\mathrm{d}} & : \text { Standard pressure angle }-20^{\circ} \\ \mathrm{a}_{\mathrm{d}} & : \text { Distance between axis } \\ \mathrm{b} & : \text { Face width } \\ \varepsilon_{\alpha} & : \text { Contact ratio } \\ \mathrm{F} & : \text { Applied single force } \\ \mathrm{F}_{\mathrm{T}} & : \text { Tangential gear force } \\ \mathrm{K}_{\mathrm{ad}} & : \text { Asymmetry factor } \\ \mathrm{h}_{\mathrm{a}} & : \text { Addendum } \\ \mathrm{h}_{\mathrm{f}} & : \text { Dedendum } \\ \mathrm{h}_{\mathrm{Fa}} & : \text { Moment arm length } \\ \mathrm{m}_{\mathrm{m}} \mathrm{m} & : \text { Module } \\ \mathrm{r}_{\mathrm{a} 1} & : \text { Addendum circle of the pinion } \\ \mathrm{r}_{\mathrm{a} 2} & : \text { Addendum circle of the gear } \\ \mathrm{r}_{\mathrm{b} 1} & : \text { Base circle of the pinion } \\ \mathrm{r}_{\mathrm{b} 2} & : \text { Base circle of the gear } \\ \sigma_{\mathrm{F} 0-\mathrm{C}} & : \text { Maximum tooth root stress } \\ \mathrm{p} & : \text { Pitch } \\ \rho_{\mathrm{F}} & : \text { Rack cutter tip radius } \\ \mathrm{S}_{\mathrm{Fn}} & : \text { Critical tooth thickness } \\ \mathrm{X} & : \text { Profile shifting } \\ \mathrm{Y}_{\mathrm{Fa}} & : \text { Form factor } \\ \mathrm{Y}_{\mathrm{Sa}} & : \text { Stress correction factor } \\ \mathrm{Y}_{\varepsilon} & : \text { Load sharing factor } \\ \mathrm{Y} \beta & : \text { Helis factor } \\ & \end{array}$


r0 : Pitch circle

z : Tooth number

\section{DECLARATIONS}

\section{Availability of data and materials}

Not applicable

\section{Competing interests}

The authors declare no conflict of interest.

\section{Funding}

This study was supported by The Commission of Scientific Research Projects of Kahramanmaras Sutcu Imam University, Project number: 2020 / 7-17 M.

\section{Authors' contributions}

OD, and CY generated the finite element model. OD, CY and FK compared and interpreted analysis results with analytical solutions. All authors read and approved the final manuscript.

\section{Acknowledgements}

Not applicable

\section{REFERENCES}

[1] R. He, P. Tenberge, X. Xu, H. Li, R. Uelpenich, P. Dong, S. Wang, Study on the optimum standard parameters of hob optimization for reducing gear tooth root stress, Mech. Mach. Theory. 156 (2021) 104128.

https://doi.org/10.1016/j.mechmachtheory.2020.104128.

[2] A. Kapelevich, Geometry and design of involute spur gears with asymmetric teeth, Mech. Mach. Theory. 35 (2000) 117-130. https://doi.org/10.1016/S0094114X(99)00002-6.

[3] F. Karpat, S. Ekwaro-Osire, K. Cavdar, F.C. Babalik, Dynamic analysis of involute spur gears with asymmetric teeth, Int. J. Mech. Sci. 50 (2008) 1598-1610. 
https://doi.org/10.1016/j.ijmecsci.2008.10.004.

[4] F.L. Litvin, Q. Lian, A.L. Kapelevich, Asymmetric modified spur gear drives:

Reduction of noise, localization of contact, simulation of meshing and stress analysis, Comput. Methods Appl. Mech. Eng. 188 (2000) 363-390.

https://doi.org/10.1016/S0045-7825(99)00161-9.

[5] Q. Wen, Q. Du, X. Zhai, A new analytical model to calculate the maximum tooth root stress and critical section location of spur gear, Mech. Mach. Theory. 128 (2018) 275286. https://doi.org/10.1016/j.mechmachtheory.2018.05.012.

[6] Iso, ISO 6336 - Calculation of load capacity of spur and helical gears - Application for industrial gears, 9085 (2002).

[7] Raymond J. Drago, An Improvement in the conventional analysis of gear tooth bending fatigue strength, Am. Gear Manuf. Assoc. (1982) Paper No:P229.24.

[8] DIN3990, Calculation of Load Capacity of Cylindrical Gears: Calculation of Tooth Strength, (n.d.).

[9] T.J. Lisle, B.A. Shaw, R.C. Frazer, External spur gear root bending stress: A comparison of ISO 6336:2006, AGMA 2101-D04, ANSYS finite element analysis and strain gauge techniques, Mech. Mach. Theory. 111 (2017) 1-9.

https://doi.org/10.1016/j.mechmachtheory.2017.01.006.

[10] F. Karpat, C. Yuce, O. Doğan, Experimental measurement and numerical validation of single tooth stiffness for involute spur gears, Meas. J. Int. Meas. Confed. 150 (2020). https://doi.org/10.1016/j.measurement.2019.107043.

[11] T.N. Costopoulos, C.A. Spitas, Optimum Gear Tooth Geometry for Minimum Fillet Stress Using BEM and Experimental Verification With Photoelasticity, 128 (2016). https://doi.org/10.1115/1.2216731.

[12] N.S. Dharashivkar, V.B. Sondur, K.D. Joshi, 3D photoelastic and finite element analysis of Asymmetric Involute Spur Gear, Int. Conf. Electr. Electron. Optim. Tech. ICEEOT 2016. (2016) 1838-1842. https://doi.org/10.1109/ICEEOT.2016.7755006.

[13] O. Can Kalay, O. Doğan, T. Gürkan Y1lmaz, C. Yüce, F. Karpat, A Comparative Experimental Study on the Impact Strength of Standard and Asymmetric Involute Spur Gears, Measurement. 172 (2020) 108950. https://doi.org/10.1016/j.measurement.2020.108950.

[14] S.M. Demet, A.S. Ersoyoğlu, Fatigue Fracture Behaviour of Asymmetric Spur Gear Tooth under Cyclic Loading, Procedia Struct. Integr. 13 (2018) 2030-2035. https://doi.org/10.1016/j.prostr.2018.12.213.

[15] K. Cavdar, F. Karpat, F.C. Babalik, Computer aided analysis of bending strength of involute spur gears with asymmetric profile, J. Mech. Des. Trans. ASME. 127 (2005) 477-484. https://doi.org/10.1115/1.1866158.

[16] V. Spitas, C. Spitas, Optimizing involute gear design for maximum bending strength and equivalent pitting resistance, Proc. Inst. Mech. Eng. Part C J. Mech. Eng. Sci. 221 (2007) 479-488. https://doi.org/10.1243/0954406JMES342. 
[17] F. Karpat, K. Cavdar, F.C. Babalik, Computer aided analysis of involute spur gears with asymmetric teeth, VDI Berichte. (2005) 145-163.

[18] G. Di Francesco, S. Marini, Asymmetric teeth: Bending stress calculation, Gear Technol. 24 (2007) 52-55.

[19] T. Costopoulos, V. Spitas, Reduction of gear fillet stresses by using one-sided involute asymmetric teeth, Mech. Mach. Theory. 44 (2009) 1524-1534. https://doi.org/10.1016/j.mechmachtheory.2008.12.002.

[20] F. Karpat, O. Dogan, S. Ekwaro-Osire, C. Yuce, A novel method for calculation gear tooth stiffness for dynamic analysis of spur gears with asymmetric teeth, ASME Int. Mech. Eng. Congr. Expo. Proc. 4A (2014) 1-8. https://doi.org/10.1115/IMECE201439402.

[21] N.L. Pedersen, Improving bending stress in spur gears using asymmetric gears and shape optimization, Mech. Mach. Theory. 45 (2010) 1707-1720. https://doi.org/10.1016/j.mechmachtheory.2010.06.004.

[22] V. Senthil Kumar, D. V. Muni, G. Muthuveerappan, Optimization of asymmetric spur gear drives to improve the bending load capacity, Mech. Mach. Theory. 43 (2008) 829858. https://doi.org/10.1016/j.mechmachtheory.2007.06.006.

[23] R. Prabhu Sekar, G. Muthuveerappan, Estimation of tooth form factor for normal contact ratio asymmetric spur gear tooth, Mech. Mach. Theory. 90 (2015) 187-218. https://doi.org/10.1016/j.mechmachtheory.2015.03.019.

[24] P. Marimuthu, G. Muthuveerappan, Investigation of load carrying capacity of asymmetric high contact ratio spur gear based on load sharing using direct gear design approach, Mech. Mach. Theory. 96 (2016) 52-74. https://doi.org/10.1016/j.mechmachtheory.2015.09.007.

[25] B. Thomas, K. Sankaranarayanasamy, S. Ramachandra, S.P. Suresh Kumar, Search method applied for gear tooth bending stress prediction in normal contact ratio asymmetric spur gears, Proc. Inst. Mech. Eng. Part C J. Mech. Eng. Sci. 232 (2018) 4647-4663. https://doi.org/10.1177/0954406217753235.

[26] O. Doğan, T.G. Yılmaz, F. Karpat, Stress analysis of involute spur gears with different parameters by finite element and graphical method, J. Fac. Eng. Archit. Gazi Univ. 33 (2018) 1493-1504. https://doi.org/10.17341/gazimmfd.416445. 